\title{
Examining the influence of supplier integration on supply chain performance in South African small and medium enterprises
}

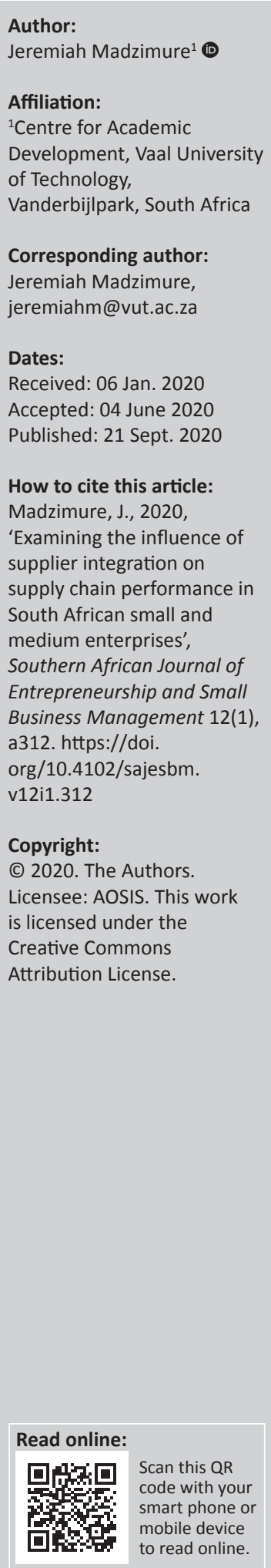

Background: As the South African economy continues to grow, the role of small and mediumsized enterprises (SMEs) as a potential source for employment creation and productivity within the country has become widely acknowledged. However, one area in which the SMEs in the country still need to develop is in their implementation of supply chain management practices, particularly their relationships with suppliers, which could result in either the failure or success of any business enterprise. Majority of studies conducted in this area have focussed on large firms, thereby creating a research gap in this area.

Aim: The aim of this study was to examine the influence of supplier integration on supply chain performance in South African SMEs.

Setting: This study was conducted in Gauteng province of South Africa.

Methods: A quantitative research methodology was employed in this study. A convenient sample comprising 283 owners and managers from SMEs drawn from the Gauteng Province was used in the study. The collected data were then analysed using Pearson's correlation and regression analysis.

Results: Positive correlations were found between supplier integration and both the tangible and intangible sub-dimensions of supply chain performance. Supplier integration also predicted both the tangible and intangible sub-dimensions of supply chain performance.

Conclusion: These results imply that to improve the performance of their supply chains, it is imperative for SMEs to ensure that linkages with their suppliers are properly aligned for improved coordination, which leads to better relationships and supply of materials. This study contributes to the literature by proposing and testing the influence of supplier integration on supply chain performance.

Keywords: supplier integration; supply chain performance; tangible dimension; intangible dimension; SMEs; South Africa.

\section{Introduction}

Small and medium enterprises (SMEs) play a crucial role in the South African economy. They contribute approximately $52 \%$ - 57\% of the country's gross domestic product (GDP) and up to $61 \%$ of the overall employment in South Africa (SME South Africa 2017). They play a crucial role in creating employment in an economy (Doern 2009:279). Over the past decade, many SMEs have shifted to the use of the Internet in business in the quest for efficiency and effectiveness (Basheka, Oluka \& Mugurisi 2011:535; Fernandes \& Vieira 2015:588; Makien, Kahkonen \& Lintukangas 2011:61). Moreover, SMEs play a very important role in supply chain management (SCM), as they may serve as producers, distributors, retailers, as well as customers (Maiga 2016:2). Therefore, it is not surprising that SMEs are the backbone of most economies in the world, including South Africa.

The National Small Business Act No. 26 of South Africa 1996, as amended in 2003, cited from Madzimure (2019:8), defined SME as:

$[A]$ separate and distinct entity including co-operative enterprises and non-governmental organisations managed by one owner or more, including its branches or subsidiaries if any is predominantly carried out in any sector or subsector of the economy mentioned in the schedule of size standards and can be classified as a SME by satisfying the criteria mentioned in the schedule of size standards. 
According to Government Gazette (2003:8) cited from Madzimure (2019:8):

[A] small enterprise in South Africa is one that employees 50 people or less and has a total turnover of up to R19m with a total asset value of $\mathrm{R} 3 \mathrm{~m}$. A medium enterprise employs 50 up to 200 people and has a total turnover of R39m with a total asset value of $\mathrm{R} 6 \mathrm{~m}$.

Hence, this study focussed only on SMEs.

Most studies on supplier integration and supply chain performance have focussed on large companies (Aharonovitz, Vieira \& Suyama 2018:284; Chang, Tsai \& Hsu 2013:38). Current knowledge involving SMEs and supplier integration in developing countries, such as South Africa, is still limited, which creates a need for further research to fill this research gap (Boehmke \& Hazen 2017:163; Karjalainen \& Kemppainen 2008:245)

The aim of this study was to examine the influence of supplier integration on supply chain performance amongst SMEs in South Africa. Furthermore, the South African government is increasingly adopting and encouraging integration with supply chain partners, such as suppliers, to improve the survival of SMEs. This is in line with the objectives of the National Development Plan (NDP), which include innovation, employment creation and the adoption of technology as mechanisms for the economic development of the country (Zarenda 2013:5). The South African government is eager to develop and streamline SME operations as SMEs make an important contribution to the economy (Maziriri \& Chivandi 2020). Many SMEs have been investing in information technology infrastructure over the past few years, 'to automate and streamline their internal business processes' (Zhao et al. 2011:368). Although these enterprises have been successful in maintaining inventories, their ordering systems and supplier management infrastructure still lack the ability to leverage the real power of inter-connectivity and integration with their suppliers to improve their supply chain performance (Ataseven \& Nair 2017:252; Sigal 2006:79).

A contribution is made to the existing literature on SMEs and supplier integration in South Africa, particularly in the context of developing countries, which was noted to be scant. Secondly, a pioneering attempt was made to apply the Configuration Theory in order to explain the interrelationships of the research constructs, in which supply chain performance was the ultimate construct. A cross-examination of the extant theory indicates that the Configuration Theory has been applied in large firms and mostly in developed countries, and to the best knowledge of the researcher, the Configuration Theory has never been applied in the context of SMEs in South Africa. The findings of this study, therefore, will fill this void that exists in academic literature. The results of this study can be used for organisational planning and possibly policy-making. They are also likely to benefit owners and managers in the SME sector, SME employee's representatives or trade unions and the government of South Africa at large.

\section{Research theory}

The theoretical rationale underpinning this study is the Configuration Theory (Miller 1986:233). According to Sinha et al. (2005:389), the Configuration Theory allows for detailed examination of the dimension of supply chain integration and performance. This theory is appropriate because it can handle complicated organisational phenomena from a holistic perspective. The configuration approach involves dominant gestalts or configurations of observable characteristics or behaviours that may lead to an outcome (Ward, Bickford \& Leong 1996:599). The Configuration Theory indicates the need to consider organisational arrangements, that is, configurations, to obtain enhanced performance. Therefore, this study considers supplier integration as the configuration of organisational resources to obtain better organisational performance.

\section{Literature review}

\section{Supplier integration}

Supplier integration refers to the 'process of interaction and collaboration between the firm and its suppliers to ensure effective flow of supplies' (Zhao et al. 2011:372). Other authors define supplier integration as a 'process of acquiring and sharing technical, operational and financial information and related knowledge' (Narasimhan, Swink \& Viswanathan. 2010). Zhao et al. (2008:371) stated that many organisations across the globe are creating co-operative, mutually beneficial partnerships with supply chain partners, owing to increasing global competition (Finger, Flynn \& Paiva 2014:821; Zhao et al. 2008:371). Zhao et al. (2008:371) further stated that companies need to implement supply chain integration to meet the new challenges of the global competitive environment.

Small and medium enterprises constantly face the problem of on-time delivery (Das, Narasimhan \& Talluri 2006:203). Through integration with suppliers, SMEs share order and inventory information with the suppliers. Furthermore, supplier integration, which includes proper communication, sharing information and working together with suppliers, can reduce upstream complexity (Bustinza et al. 2017:35; Das et al. 2006:204). The benefits of supplier integration are that it enhances responsiveness, flexibility and timesaving (Boehmke \& Hazen 2017:163). Supplier integration also plays a key role in reducing transaction costs through the reduction of uncertainties and production costs (Das et al. 2006:197; Flynn, Hou \& Zhao 2010:58; Kang et al. 2018:1749; Zhao et al. 2008:368). Therefore, supplier integration has a positive impact on operational performance (Devaraj, Krajewski \& Wei 2007:1119). In supplier integration, opportunistic behaviours are greatly reduced under shared visions and cooperative goals (Kanyoma, Agbola \& Oloruntoba 2018:1005; Wong, Tjosvold \& Yu 2005:782).

\section{Supply chain performance}

Supply chain performance is defined as the extended supply chain's activities in meeting end-customer requirements, 
including product availability, on-time delivery, and all the necessary inventory and capacity in the supply chain to deliver that performance in a responsive manner.

One of the key aspects of successful supply chain performance is co-operation and mutual decision-making between trading partners (Botta-Genoulaz et al. 2010:834). Supply chain integration practices, such as collaboration practices and information exchanges between partners, become essential within any supply chain, as they contribute to increased performance (Sakka \& BottaGenoulaz 2009:1; Srinivasan, Mukherjee \& Gaur 2011:268; Zhao, Feng \& Wang 2015:162). Overall, supply chain performance is recognised as an important factor for improving competitive advantage (Amaratunga \& Baldry 2002:218; Chang et al. 2013:35; Shou et al. 2018:354). In this study, tangible and intangible supply chain performance measures, as suggested by Gunasekaran, Patel and Tirtiroglu (2001:82) and Anvari, Nayeri and Razavi (2011:63), were considered.

\section{Conceptual framework and hypotheses}

The study tested the conceptual framework presented in Figure 1. The predictor variable is supplier integration, which is linked to both tangible and intangible supply chain performance. Tangible supply chain performance refers to measures of performance, such as cost, profits and cash turnover. The intangible dimensions include satisfaction, lead time and capacity utilisation.

It is suggested that, as a result of integration within firms, a positive organisational performance might be enhanced because of sharing of risks; sharing of business information, which includes demand forecasts, inventory level and production planning decisions; as well as synchronising business process (So \& Sun 2010:474). The relationships between integration and SME performance have been extensively studied (Kim 2009:328; Kristal, Huang \& Roth 2010:415; Lau, Yam \& Tang 2007:1), and these findings confirm that integration can be transformed into competitive capabilities thus contributing to positive supply chain performance. In addition to this, there are other researchers who confirmed the positive significant relationship between supplier integration and supply chain performance (Bowersox, Closs \& Stank 1999; Flynn et al. 2010; Frohlich \& Westbrook 2001; Zhao et al. 2015:78). Thus, this study is

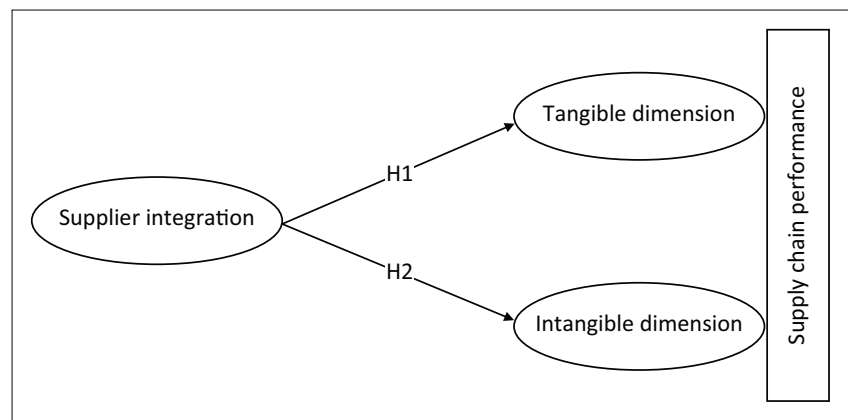

FIGURE 1: Conceptual framework. intended to confirm or disconfirm the findings of this relationship from other researchers.

Based on the above conceptual framework and the relationship between supplier integration and supply chain performance, the following hypotheses were formulated for testing in the study:

H1: Supplier integration exerts a positive and significant influence on tangible supply chain performance.

H2: Supplier integration exerts a positive and significant influence on intangible supply chain performance.

The next section discusses the research methodology employed in this study.

\section{Research methodology Research approach and sample}

A quantitative research methodology was adopted for this study, as according to Borrego, Douglas and Amelink (2009:54), a study of cause and effect relationships amongst different constructs is well suited for a quantitative research strategy. As this study assessed the relationships between supplier integration and supply chain performance, it was appropriate to use a quantitative approach because it would have been very difficult to include all 283 participants in a qualitative research. It was also necessary to generalise the results to other environments of SMEs, hence the need to choose a quantitative approach. This study also used a quantitative method to assist in establishing the causal relationship or influence of supplier integration and supply chain performance amongst SMEs. A cross-sectional survey design, which involves a descriptive study of a situation at one specific point in time, was adopted in this study to determine the opinions of owners and managers in SMEs. A cross-sectional survey offers advantages, such as allowing researchers to collect a large amount of information quickly, and it is usually inexpensive, thereby making it fit for this study.

A total of 350 questionnaires were distributed to respondents, of which 294 were returned, and 11 were discarded owing to incomplete responses to different parts of the questionnaire. A total of 283 questionnaires were finally used in the study. The 283 respondents were owners and managers of SMEs that were based in the Gauteng Province, South Africa. The study only requires inputs from managers and owners of SMEs because the researcher believed they will provide the most relevant information for the study. As no established database could be found to act as a sample frame, the business telephone directory was used as a starting point to come up with a list of SMEs in Gauteng. Telephone calls were made to establish whether these businesses were still in existence, if they qualified to be SME business enterprises in terms of the definition and whether they would grant permission to conduct the study in their organisations. A non-probability sampling method in the form of a convenience sampling technique was employed to select the participants in this 
study, as there was no single sample frame from which the list of SMEs could be drawn. A simple random sampling was also adopted to avoid bias.

\section{Data collection and instrumentation}

Data were collected through a face-to-face survey method using a structured questionnaire. The measurement instruments used in this study were adapted from previous studies. Supplier integration was measured using eight items adapted from Zhao et al. (2013), and the reliability coefficient alpha was 0.87 . Supply chain performance was measured using 10 items, adapted from Chang et al. (2013), with the reliability coefficient alpha of 0.85 . All measurement scales were measured using five-point Likert-type scales, anchored by $1=$ strongly disagree and $5=$ strongly agree. The Likerttype scale was chosen because it was very easy to code and analyse directly from the questionnaires, which were distributed to SMEs for a period of 3 months between May and July 2017.

\section{Data analysis}

Data were subjected to statistical analysis using the descriptive statistics technique in the form of percentages. Regression analysis and correlation was performed using the Statistical Package for Social Sciences (SPSS), version 24.0 for Windows.

\section{Research results \\ Biographic information of participating enterprises}

Of the 283 SMEs that participated in the study, $44.5 \%(n=126)$ of the firms employed between 151 and 200 employees, whilst 37.5\% ( $n=106)$ of the firms employed between 101 and 150 employees. The analysis further shows that $27.5 \%(n=78)$ of the firms earn between R20 to R30m in turnover.

Approximately $37.1 \%(n=105)$ have a turnover of between R30m and R39m per year. Males constituted 54.0\% $(n=153)$ and females constituted $46.0 \%(n=130)$ of the sample. Those older than 60 years of age comprised $8.1 \%(n=23)$ of the sample. The majority, $43.8 \%$, $(n=124)$ of the sample, was in the range of 50-59 years. The 40-49 age range comprised $38.9 \%(n=110)$ of the sample. A small percentage, $1.4 \%$ $(n=4)$, was younger than 30 years.

\section{Exploratory factor analysis}

The different scales used in the study were tested for unidimensionality through exploratory factor analysis. Prior to factor analysis, 'the Bartlett's Test of Sphericity and the Kaiser-Meyer-Olkin (KMO) measure of sampling adequacy was computed to establish whether the data were suitable for factor analysis' (Madzimure 2020:4) (see Table 1). Both tests provided an indication that the data set was suitable for factor analysis. However, four items were deleted from the supply chain performance scales (SCP5, SCP6, SCP8 and SCP14) because they had factor loadings below the
TABLE 1: Kaiser-Meyer-Olkin measure of sampling adequacy and Barlett's test. Kaiser-Meyer-Olkin Barlett's test of sphericity sampling adequacy Approximate chi-square Degrees of freedom Significance \begin{tabular}{llll}
\hline 0.821 & 541.701 & 42 & 0.000 \\
\hline
\end{tabular}

TABLE 2: Correlation analysis results

\begin{tabular}{lccccc}
\hline Variable & Mean & Reliability A & SI & SCPTD & SCPID \\
\hline SI & 3.90 & 0.89 & 1.00 & - & - \\
SCPTD & 3.80 & 0.78 & $0.563 \dagger$ & 1.00 & - \\
SCPID & 3.91 & 0.79 & $0.576 \dagger$ & $0.565 \dagger$ & 1.00 \\
\hline
\end{tabular}

Note: Scale: 1 = strongly agree; 2 = disagree; 3 = neutral; 4 = agree; 5 = strongly agree. $\mathrm{SI}$, supplier integration; SCPTD, supply chain performance: tangible dimension; SCPID, supply chain performance: intangible dimension.

$\dagger$, Correlation is significant at the 0.01 level (two-tailed).

recommended value of 0.5 . The composite reliability (CR), average variance extracted (AVE) and Cronbach's alpha were $0.88,0.84$ and 0.89 , respectively, for supplier integration. The CR, AVE and Cronbach's alpha were 0.93, 0.82 and 0.78, respectively, for tangible supply chain performance. Lastly, for intangible supply chain performance, CR was 0.79, AVE was 0.82 and Cronbach's alpha was 0.79 .

\section{Validity and reliability}

Reliability 'measures the quality of the research instrument used, in this case, the research questionnaire' (Sarantakos 2005:88). Reliability in this study was ascertained using Cronbach's alpha coefficient. For the Cronbach's alpha coefficient and the $\mathrm{CR}$, the recommended values should be greater than or equal to 0.70 for each scale (Babbie 2013:49). As shown under the explanatory factor analysis, the Cronbach's alpha values for the three scales ranged between 0.78 and 0.89 , which were above the recommended value of 0.70 (Wade \& Love 2006), thereby confirming that reliability was satisfactory in this study. The CR ranged from 0.79 to 0.93 , which further confirms the reliability of the instrument.

Validity refers 'to the degree to which evidence supports any inferences a researcher makes, based on the data' (McKinney 2011:6). In this study, four validities, namely, face, content, convergent and predictive validities were measured. To ensure face validity, the research study used several experts in SCM to judge the questions independently. To ascertain content validity, a pilot study was conducted with a conveniently selected sample of 42 respondents, as recommended by Wade and Love (2006:135). To ascertain convergent validity, the factor loadings for each item were checked. Most of the values were over 0.50 , with few very close to 0.5 , and were accepted. To check for predictive validity, regression analysis was used. As shown in Tables 2 and 3 , beta values between the dependent and independent values were positive, indicating that predictive validity was satisfactory in this study (Babbie 2013; McKinney 2011).

\section{Correlations and regression results}

The association between supplier integration and the two dimensions of supply chain performance was tested using Pearson's correlation. The results are shown in Table 2. 
As revealed in Table 2, there were strong positive inter-factor correlations between the three constructs. There was a strong positive and significant correlation between supplier integration and the tangible supply chain performance $(r=0.563 ; p<0.01)$. Another strong positive correlation $(r=0.576 ; p<0.01)$ was found between supplier integration and intangible supply chain performance. There was also a strong positive correlation $(r=0.565 ; p<0.01)$ between both dimensions of supply chain performance. The findings of this study suggest that supplier collaboration is a very important factor in influencing supply chain performance in SMEs.

An analysis of the mean scores (Table 2) shows that the three constructs had averages varying between 3.80 and 3.91 . These scores depict a close inclination towards the agree point on the Likert-type scale. This therefore implies that most respondents concurred that the implementation of supplier integration and the performance of the respective SME supply chains were both satisfactory (Babbie 2013).

\section{Regression analysis results}

To test whether the supplier integration predicted both dimensions of supply chain performance, regression analysis using the 'enter' method was applied. Two regression models (Tables 3 and 4) were computed. The assumptions of regression were fulfilled by testing for multicollinearity in both regression models. The tests proved that variance inflation factors (VIF) were below the recommended maximum threshold of 10 and that tolerance values were less than the recommended minimum value of 0.2 for both regression models (O'Brien 2007:674). Thus, multicollinearity statistics did not indicate a serious threat to this study.

As shown in Table 3, supplier integration $\left(R^{2}=0.317\right)$ explained nearly $32 \%$ of the variance tangible supply chain performance.

As indicated in Table 4, supplier integration $\left(R^{2}=0.332\right)$ explained $33 \%$ of the variance tangible supply chain performance.

\section{Discussion of the results}

As shown in Table 3, supplier integration has a positive and significant relationship with tangible supply chain

TABLE 3: Regression model 1: Supplier integration and supply chain performance - Tangible dimension.

\begin{tabular}{lccc}
\hline Independent variable & \multicolumn{3}{c}{$\begin{array}{c}\text { Dependent variable }=\text { Supply chain performance: } \\
\text { Tangible dimension }\end{array}$} \\
\cline { 2 - 4 } & $\boldsymbol{B}$ & $\boldsymbol{T}$ & $\boldsymbol{p}$ \\
\hline Supplier integration & 0.563 & 11.795 & 0.000 \\
\hline
\end{tabular}

Note: $R=0.563 ; R^{2}=0.317$.

TABLE 4: Regression model 2: Supplier integration and supply chain performance - Intangible dimension.

\begin{tabular}{lccc}
\hline Independent variable & \multicolumn{3}{c}{$\begin{array}{c}\text { Dependent variable = Supply chain performance: } \\
\text { Intangible dimension }\end{array}$} \\
\cline { 2 - 4 } & $\boldsymbol{B}$ & $\boldsymbol{T}$ & $\boldsymbol{p}$ \\
\hline Supplier integration & 0.576 & 12.220 & 0.000 \\
\hline
\end{tabular}

Note: $R=0.576 ; R^{2}=0.332$. performance. This study posited a positive influence of supplier integration on tangible supply chain performance, and the results of this study confirmed this relationship. The results of the regression analysis show a positive beta value $(\beta=0.563 ; p=0.000 ; t=11.795)$, which validates the hypothesised positive influence of supplier integration on tangible supply chain performance. Hypothesis 1 is therefore supported.

Table 3 reveals that supplier integration has a positive and significant linear relationship with intangible supply chain performance. This study posited a positive influence of supplier integration on intangible supply chain performance, and the results of this study confirmed that relationship. A positive beta value $(\beta=0.576 ; p=0.000 ; t=12.220)$ validates the hypothesised positive influence that supplier integration has on intangible supply chain performance. Hypothesis 2 is therefore supported.

The results of this study are consistent with previous findings (Childerhouse \& Towill 2003; Giménez \& Ventura 2005), which show convincing empirical evidence for the relationship between supplier integration and performance. However, some studies (Droge et al. 2004; Flynn et al. 2010) found different results. The findings of this study suggest that supplier integration is critical in improving firm performance, especially in small business. The results further show the need to co-operate and collaborate with their key suppliers (thus supplier integration) in order to survive, compete, prosper and gain competitive advantage and achieve excellence.

\section{Conclusion and managerial implications}

The aim of this study was to examine the influence of supplier integration on supply chain performance. The study considered the tangible and intangible dimensions of supply chain performance. The results of the study suggest that supplier integration is an important factor in influencing supply chain performance in SMEs. The study suggest that SME owners and managers need to prioritise supplier collaboration by hosting regular workshops, seminars, trainings and meetings to enhance supplier integration because the study shows a strong positive relationship between the constructs. As the study also found the relationship between supplier integration and intangible supply chain performance to be positively significant, it is important for SME owners and management to create further synergies with their key suppliers, as this will enable them to prosper and gain competitive advantage. To co-operate and collaborate more often, forums such as education forums and business forums, amongst other forums, aimed at bringing together all supply chain members to discuss business issues could be created. These discussion forums will have to happen often, as they provide a platform for robust discussions that may lead to enhanced supplier integration, which further boosts SME performance. 


\section{Limitations and suggestions for future research}

The study focussed only on one province, therefore making it difficult to generalise the results of this study. Further research focussing on all nine provinces could provide indepth information. Although this study used supplier integration as the only variable, other variables could be further explored and incorporated into the framework.

For example, relationship between marketing variables can enhance firm performance, implying that a potential influence on supply chain performance might exist. Future research is needed for examining the relationship between supplier integration, schedule attainment and competitive performance. In this study, supply chain performance was measured by tangible and intangible dimensions. Further research could apply different supply chain performance dimensions such as the supply chain operations reference (SCOR) model, output resources and flexibility, amongst others.

\section{Acknowledgements}

The author would like to thank Almighty God.

\section{Competing interests}

The author has declared that no competing interest exists.

\section{Author's contributions}

I declare that I am the sole author of this research article.

\section{Ethical consideration}

This article followed all ethical standards for carrying out research.

\section{Funding information}

This research received no specific grant from any funding agency in the public, commercial or not-for-profit sectors.

\section{Data availability statement}

Data sharing is not applicable to this article as no new data were created or analysed in this study.

\section{Disclaimer}

The views and opinions expressed in this article are those of the author and do not necessarily reflect the official policy or position of any affiliated agency of the author.

\section{References}

Aharonovitz, M.C.S., Vieira, J.G.V. \& Suyama, S.S., 2018, 'How logistics performance is affected by supply chain relationships', The International Journal of Logistics Management 29(1), 284-307. https://doi.org/10.1108/IJLM-09-2016-0204

Amaratunga, D. \& Baldry, D., 2002, 'Moving from performance to performance management', Facilities 20(5/6), 217-223. https://doi.org/10.1108/026327 70210426701
Anvari, G., Nayeri, T. \& Ravazi, P., 2011, 'Supply chain management and its influence on operational performance', Journal of Operations and Supply Chain Management 4(2), 56-70. https://doi.org/10.12660/joscmv4n2p56-70

Ataseven, C. \& Nair, A., 2017, 'Assessment of supply chain integration and performance relationships: A meta-analytic investigation of the literature', International Journal of Production Economics 185, 252-265. https://doi.org/10.1016/ j.ijpe.2017.01.007

Babbie, E., 2013, The practice of social research, 13th edn., Cengage Learning Custom Publishing, Wadsworth, CA.

Basheka, B., Oluka, P. \& Mugurisi, P., 2011, 'Compliance to public procurement reform in developing countries: The conceptual perspective from Uganda', International Journal of Procurement Management 4(5), 535-548. https://doi.org/10.1504/ IJPM.2011.042171

Boehmke, B.C. \& Hazen, B.T., 2017, 'The future of supply chain information systems: The open source ecosystem', Global Journal of Flexible Systems Management 18(2), 163-168. https://doi.org/10.1007/s40171-017-0152-x

Borrego, M., Douglas, E.P. \& Amelick, C.T., 2009, 'Quantitative, qualitative \& mixed research methods in engineering education', Journal of Engineering Education 98(1), 53-66. https://doi.org/10.1002/j.2168-9830.2009.tb01005.x

Botta-Genoulaz, V., Campagne, J.P., Llerena, D. \& Pellegrin, C., 2010, Supply chain performance: Collaboration, alignment and coordination, John Wiley \& Sons, London.

Bowersox, D.J., Closs, D.J. \& Stank, T.P., 1999, 21st century logistics: Making supply chain integration a reality, Council of Logistics Management, Michigan State University, East Lansing, MI.

Bustinza, O.F., Gomes, E., Vendrell-Herrero, F. \& Baines, T., 2017, 'Product-service innovation and performance: The role of collaborative partnerships and R\&D intensity', R\&D Management 49(1), 33-45. https://doi.org/10.1111/radm.12269

Chang, H.H., Tsai, Y.C. \& Hsu, C.H., 2013, 'E-procurement \& supply chain performance', International Journal of Management 18(1), 34-51. https://doi.org/10.1108/ 13598541311293168

Childerhouse, P. \& Towill, D.R., 2003, 'Simplified material flow holds the key to supply chain integration', The International Journal of Management Science 31, 17-27.

Das, A., Narasimhan, R. \& Talluri, S., 2006,' Supplier integration - Finding an optimal configuration', Journal of Operations Management 24(5), 563-582. https://doi. org/10.1016/j.jom.2005.09.003

Devaraj, S., Krajewski, L. \& Wei, J.C., 2007, 'Impact of e-business technology in operational performance: The role of production information integration in the supply chain', Journal of Operations Management 25(6), 1119-1216. https://doi. org/10.1016/j.jom.2007.01.002

Doern, R., 2009, 'Investigating barriers to SME growth and development in transition environments: a critique and suggestions for developing the methodology', International Small Business Journal 27(3), 275-305.

Droge, C., Jayaram, J. \& Vickery, S.K., 2004, 'The effects of internal versus external integration practices on time-based performance and overall firm performance', Journal of Operations Management 22, 557-573.

Fernandes, T. \& Vieira, V., 2015, 'Public e-procurement impacts in small -\&-medium enterprises', International Journal of Procurement Management 8(5), 587-607. https://doi.org/10.1504/IJPM.2015.070904

Finger, A.B., Flynn, B.B. \& Paiva E.L., 2014, 'Anticipation of new technologies: Supply chain antecedents and competitive performance', International Journal of Operations Production Management 34(6), 807-828. https://doi.org/10.1108/ IJOPM-09-2012-0386

Flynn, B.B., Hou, B. \& Zhao, X., 2010, 'The impact of supply chain integration on performance: A Contingency \& Configuration Approach', Journal of Operations Management 28, 58-71.

Frohlich, M.T. \& Westbrook, R., 2001, 'Arcs of integration: An international study of supply chain strategies', Journal of Operations Management 19(2), 185-200. https://doi.org/10.1016/S0272-6963(00)00055-3

Giménez, C. \& Ventura, E., 2005, 'Supply chain management as a competitive advantage in the Spanish grocery sector', International Journal of Logistics Management 14(1), 77-88. https://doi.org/10.1108/09574090310806558

Government Gazette, 2003, No 26 National Small Business Amendment Act Parliament of the Republic of South Africa, Cape Town, p. 461, 1-10.

Gunasekaran, A., Patel, C. \& Tirtiroglu, E., 2001, 'Performance measures and metrics in a supply chain environment', International Journal of Operations and Production Management 21(2), 71-87. https://doi.org/10.1108/01443570110358468

Kang, M., Yang, M.A., Park, Y. \& Huo, B, 2018, 'Supply chain integration and its impact on sustainability', Industrial Management Data Systems 118(9), 1749-1765. https://doi.org/10.1108/IMDS-01-2018-0004

Kanyoma, K.E., Agbola, F.W. \& Oloruntoba, R., 2018, 'An evaluation of supply chain integration across multi-tier supply chains of manufacturing-based SMEs in Malawi', International Journal of Logistics Management 29(3), 1001-1024. https://doi.org/10.1108/IJLM-10-2017-0277

Karjalainen, K. \& Kemppainen, K., 2008, 'The involvement of small-\&-medium sized enterprises in public procurement: Impact of resource perceptions electronic systems \& enterprise size', Journal of Purchasing \& Supply Management 19(4), 238-246. https://doi.org/10.1016/j.pursup.2008.08.003

Kim, S.W., 2009, 'An investigation on the direct and indirect effect of supply chain integration on firm performance', International Journal of Production Economics 119(2), 328-346. https://doi.org/10.1016/j.ijpe.2009.03.007

Kristal, M.M., Huang, X. \& Roth, A.V., 2010, 'The effect of an ambidextrous supply chain strategy on combinative competitive capabilities and business performance', Journal of Operations Management 28(5), 415-429. https://doi.org/10.1016/j. jom.2009.12.002 
Lau, A.K.W., Yam, R.C.M. \& Tang, E., 2007, 'The impacts of product modularity on competitive capabilities and performance: An empirical study' Internal Journal of Production Economics 105(1), 1-20. https://doi.org/10.1016/j.ijpe.2006.02.002

Madzimure, J., 2019, 'The influence of strategic networks and logistics integration on firm performance among small and medium enterprises', Southern African Journal of Entrepreneurship and Small Business Management 11(1), a282. https://doi. org/10.4102/sajesbm.v11i1.282

Madzimure, J., 2020, 'Enhancing supplier integration through e-design and e-negotiation', Southern African Journal of Entrepreneurship and Small Business Management 12(1), 1-8. https://doi.org/10.4102/sajesbm.v11i1.282

Maiga, A.S., 2016, 'Assessing the impact of supply chain integration on firm competitive capability', International Journal of Operations Research and Information Systems 7(1), 1-2. https://doi.org/10.4018/IJORIS.2016010101

Makien, J., Kahkonen, A. \& Lintukangas, K., 2011, 'E-procurement as a success factor in co-operative purchasing', Journal of Public Procurement Management 4(1), 56-70.

Maziriri, E.T. \& Chivandi, A., 2020, 'Modelling key predictors that stimulate the entrepreneurial performance of small and medium-size enterprises (SMEs) and poverty reduction: Perspectives from SME managers in emerging economy', Acto Commercii 20(1), 1-15. https://doi.org/10.4102/ac.v20i1.773

Mckinney, K., 2011, Quantitative analysis and reporting: Telling a story with numbers, Sage, Thousand Oaks, CA.

Miller, D., 1986, 'Configuration of strategy and structure: Towards a synthesis', Strategic Management Journal 7(3), 233-249. https://doi.org/10.1002/smj.4250070305

Narasimhan, R., Swink, M. \& Viswanathan, M., 2010, 'On decision for integration implementation: An examination of complementarities between product-process technology integration and supply chain integration', Decision Sciences 41(2) 355-372. https://doi.org/10.1111/j.1540-5915.2010.00267.x

O'Brien, R.M., 2007, 'A caution regarding rules of thumb for variance inflation factors', Quality \& Quantity 41(5), 673-690. https://doi.org/10.1007/s11135-006-9018-6

Sakka, O. \& Botta-Genoulaz, V., 2009, A model of factors influencing the supply chain performance, INSA de Lyon, LIESP, pp. 1-6, Universitea de Lyon, Lyon.

Sarantakos, S., 2005, Social research, 3rd edn., Macmillan, New York, NY.

Shou, Y., Li, Y., Park, Y. \& Kang M., 2018, 'Supply chain integration and operational performance: The contingency effects of production systems', Journal of Purchasing Supply Management 24(4), 352-360. https://doi.org/10.1016/j.pursup.2017.11.004

Sigal, M., 2006, 'E-procurement diffusion on the supply chain of food service operators: An explanatory study in Greece', Information Technology \& Tourism 8(2), 79-90. https://doi.org/10.3727/109830506778001438
Sinha, K., Kingshuk, K., Van De Ven, H. \& Andrew, H., 2005, 'Designing work within and between organisations', Organisational Sciences 16(4), 389-408.

SME South Africa, 2017, Why SA SMEs can expect better prospects in 2017, viewed 04 March 2020, from http://www.smesouthafrica.co.za/17024/3-reasons-SASMEs-can-expect-a-better-2017/.

So, S. \& Sun, H., 2010, 'Supplier integration strategy for lean manufacturing adoption in electronic-enabled supply chains', Supply Chain Management: An International Journal 15(6), 474-487. https://doi.org/10.1108/13598541011 080455

Srinivasan, M., Mukherjee, D. \& Gaur, A., 2011, 'Buyer-supplier partnership quality and supply chain performance: Moderating role of risks, and environmenta uncertainty', European Management Journal 29(4), 260-271. https://doi. org/10.1016/j.emj.2011.02.004

Wade, M.R. \& Love, S., 2006, 'Development and validation of a perceptual instrument to measure e-commerce performance', International Journal of Electronic Commerce 10(2), 123-146. https://doi.org/10.2753/JEC1086-4415100205

Ward, P.T., Bikford, D.J. \& Leong, G.K., 1996, 'Configurations of manufacturing strategy, business strategy, environment and structure', Journal of Management 22(4), 597-626. https://doi.org/10.1177/014920639602200404

Wong, A.S.H., Tjosvold, D. \& Yu, Z.Y., 2005, 'Organisational partnerships in China: Selfinterest, goal independence \& opportunism', Journal of Applied Psychology 90(4), 782-791.

Zarenda, H., 2013, South Africa's National Development Plan and its implications for regional development, Tralac, Stellenbosch.

Zhao, G., Feng, T. \& Wang, D., 2015, 'Is more supply chain integration always beneficial to financial performance?', Industrial Marketing Management Journal 45, 162-172. https://doi.org/10.1016/j.indmarman.2015.02.015

Zhao, L., Huo, B., Sun, L. \& Zhao, X., 2013, 'The impact of supply chain risk on supply chain integration and company performance: A global investigation', International Journal of Supply Chain Management 18(2), 115-131. https://doi.org/10.1108/ 13598541311318773

Zhao, X., Huo, B., Selen, W. \& Yeung, J.H.Y., 2011, 'The impact of relationship commitment on the integration between manufacturers and customers in supply chain', Journal of Operations Management 29(1-2), 368-388. https://doi. org/10.1016/j.jom.2007.08.002

Zhao, X.B., Huo, B.B., Flynn, B. \& Yeung, L., 2008, 'The impact of power and relationship commitment on the integration between manufacturers and customers in a supply chain', Journal of Operations Management 26(3), 368-388. https://doi. org/10.1016/j.jom.2007.08.002 